\title{
Vibration elicited vasoconstrictor reflex in Raynaud's phenomena
}

\author{
N OLSEN, O U PETRING \\ From the Department of Clinical Physiology and Nuclear Medicine and Clinic of Occupational Medicine, \\ Rigshospitalet, University of Copenhagen, Copenhagen, Denmark
}

ABSTRACT The fingers of seven women with primary Raynaud's phenomenon (PRP), 10 female controls, seven men with vibration induced white finger (VWF), and eight male controls were exposed to vibration and the relative change in finger capillary blood flow was measured by an atraumatic

${ }^{133}$ xenon washout technique without and during proximal nervous blockade. All four groups showed a vasoconstriction to vibration $(p \leqslant 0.02)$ which was abolished by proximal nervous blockade. Women with PRP had an augmented response to vibration $(p<0.01)$ and men with VWF had a normal response $(p>0 \cdot 10)$ when compared with that of their respective sex matched controls. The results show the existence of a vibration elicited central sympathetic vasoconstrictor reflex in the normal finger and in fingers affected by PRP and VWF. The results indicate a hyperreactivity of the central sympathetic nervous system in PRP and VWF and a dysfunction of the peripheral sensory nerve fibres in subjects with VWF. The described vibration test may be of guidance in the differentiation of PRP from VWF.

Acute vibration induces a decrease in blood flow in normal fingers ${ }^{\prime}$ and this vasoconstrictor response seems to be augmented in some subjects with vibration induced white finger (VWF). ${ }^{2}$ It is uncertain if the vasoconstriction is due to a local or a central reflex mechanism. ${ }^{12}$ The vasomotor response to acute vibration has never been investigated in subjects with primary Raynaud's phenomenon (PRP). Recently we investigated the postural vasoconstrictor reflexes by a local ${ }^{133}$ xenon washout technique ${ }^{34}$ in women with PRP, men with VWF, and their respective sex matched controls. The results indicated a hyperreactivity of the central sympathetic nervous system to orthostatic stress in both types of Raynaud's phenomenon (RP) and normal function in the digital arterioles and postganglionic sympathetic nerve fibres. ${ }^{3}$ These postural reflexes, however, do not affect the sensory nerve fibres as opposed to acute vibration exposure. The aim of the present study was to investigate the effect of acute vibration exposure on finger capillary blood flow without and during proximal nerve block by the same technique ${ }^{4}$ and in the same subjects as recently examined. ${ }^{3}$

Accepted 11 May 1987

\section{Subjects and methods}

Seven women with PRP, 10 female controls, seven men with VWF, and eight male controls took part in the investigation. All subjects gave informed consent to the study which was approved by the local ethical committee. The subjects with VWF had previously been diagnosed in our hospital's clinic of occupational medicine. Most other subjects were medical students. The subjects were selected according to the following criteria, confirmed at a medical interview: age 21-49; healthy except for RP; no abuse of alcohol; no medication; no history of digital gangrene; controls and subjects with PRP never worked with vibrating hand tools; PRP and VWF diagnosed in accordance with the criteria given by Allen and Brown ${ }^{5}$ and by Taylor and Pelmear. ${ }^{6}$ The severity of RP was assessed according to a modified Taylor-Pelmear scale ${ }^{6}$ : stage 1 blanching of one or more fingertips; stage 2 blanching of one or more fingers; and stage 3 extensive blanching of most fingers with frequent episodes during summer and winter. No subjects with VWF had changed occupation to avoid further exposure to vibration because of severity of symptoms. Table 1 gives the characteristics of the four groups. Both groups with RP were older than their sex matched controls. Four 
Table 1 Characteristics of seven men with vibration induced white finger (VWF), eight male controls (MC), seven women with primary Raynaud's phenomenon (PRP), and 10 female controls $(F C)$. MABP and SPG denote mean arterial blood pressure on the upper arm and systolic pressure gradient from upper arm to finger respectively, both at rest. Stage of $V W F$ and $P R P$ refers to a modified Taylor-Pelmear scale evaluating the severity of the disorders. (Values are given as the median with the range in parentheses)

\begin{tabular}{|c|c|c|c|c|}
\hline & $V W F$ & $M C$ & $P R P$ & $F C$ \\
\hline $\begin{array}{l}\text { Age (y) } \\
\text { Stage of VWF and PRP } \\
\text { No of affected fingers } \\
\text { Duration of VWF and PRP (y) } \\
\text { Exposure to vibration }(y) \\
\text { Latent period of VWF (y) } \\
\text { MABP (mm Hg) } \\
\text { SPG (mm Hg) }\end{array}$ & $\begin{array}{l}41(28-47)^{*} \\
2(1-3) \\
4(3-10) \\
9(3-19) \\
15(12-21) \\
8(2-20) \\
93(87-100) \\
5(0-15)\end{array}$ & $\begin{array}{l}89(82-95) \\
10(0-20)\end{array}$ & $\begin{array}{l}32(22-39)^{*} \\
2(1-3) \\
8(6-10) \\
9(5-25)\end{array}$ & $\begin{array}{l}88(72-100) \\
10(0-15)\end{array}$ \\
\hline
\end{tabular}

*Significantly different from sex matched controls $(\mathrm{p}<0.05)$.

subsamples were selected as follows to investigate whether the results could be explained by these differences in age: the four youngest men with VWF, the four oldest male controls, the four youngest women with PRP, and the four oldest female controls. In these subsamples there was no significant age difference between men with VWF and male controls $(p>0 \cdot 10)$ or between women with PRP and female controls $(p>0 \cdot 10)$.

The subjects had abstained from tobacco, alcohol, and work with vibrating tools for at least three hours before the study. They were studied at a constant room temperature $\left(24.0^{\circ} \mathrm{C} \pm 0.5\right)$ after at least 45 minutes of rest, when they felt comfortably warm without sweating. None of the subjects had ischaemic or atrophic fingers on visual inspection. The fingers reported to be most affected were investigated in subjects with RP. In the controls the same fingers (2-4 finger) were used as in the subjects with RP. Blood pressures at rest were measured with the arm and finger at heart level. Arm blood pressure was measured auscultatorily with a 12 $\mathrm{cm}$ broad cuff. All subjects were found to be normotensive. Mean arterial blood pressure was estimated as diastolic pressure plus $1 / 3$ pulse pressure and is given in table 1. Finger systolic blood pressure was measured by strain gauge plethysmography. ${ }^{7}$ The systolic pressure gradient from arm to finger was 20 $\mathrm{mm} \mathrm{Hg}$ or less in all subjects (table 1). Thus none had functional signs of significant obstructions of the supplying arteries to the fingers. ${ }^{8}$ It was therefore assumed that all subjects with RP had vasospastic disease.

The apparatus for vibration exposure (Brüel and Kjær instruments) consisted of a vibration exciter equipped with a handle and powered from a power amplifier connected to a sine random generator. The acceleration of the handle was monitored with an accelerometer attached to the handle and connected to a vibration meter. A vertical sinusoidal acceleration level of $100 \mathrm{~m} / \mathrm{s}^{2}$ (root-mean-square value, unweigh- ted) at a frequency of $125 \mathrm{~Hz}$ was used. The volar side of the distal interphalangeal joints of the index, middle, and ring fingers, which included the finger tested, were placed on the upper side of the handle. During the investigation the fingers rested only by their own weight on the handle to ensure contact. The subjects sat comfortably on a chair at complete rest with straight back, the arm carefully immobilised, and the fingers at the level of the jugular notch. Before the measurements the subjects had familiarised themselves with the sitting posture and with the vibration exposure to minimise transient alterations in finger blood flow. ${ }^{9}$

The relative capillary blood flow was measured on the dorsum of the distal interphalangeal joint, which is a region without arteriovenous anastomoses. ${ }^{10} \mathrm{~A}$ skin area of $12 \mathrm{~mm}$ in diameter was labelled epicutaneously with ${ }^{133}$ xenon in isotonic solution $(370 \mathrm{MBq} / \mathrm{ml})$ during two minutes by a modified, atraumatic labelling technique." The decline of radioactivity in the labelled area was monitored externally from one minute after the labelling by a $\mathrm{NaI}(\mathrm{T} 1)$ scintillation detector with the crystal surface $9 \mathrm{~cm}$ above the skin and a wide collimation. The activity was printed out in intervals of five or 10 seconds. The disappearance of the radioactive depot was monitored (1) before, (2) during, and (3) after exposure to vibration. Each period lasted about two minutes. At least 30 minutes after this exposure to vibration the labelling of the finger and the measurements were repeated during digital nerve block produced by application of $4 \mathrm{ml}$ $2 \%$ lignocaine at the base of the finger. The small nerve fibres including the sympathetic fibres were considered to be blocked when the subjects had lost the perception of pinprick and temperature. The measurement started after the finger systolic blood pressure was normalised. A control experiment was performed during steady state conditions in seven subjects to ascertain that the undisturbed washout rate during the initial six to seven minutes was monoexponential. ${ }^{12}$ 
The count rates, corrected for background activity, were plotted versus time in semilogarithmic scale. In both tests the washout rate constant $\left(\mathrm{min}^{-1}\right)$ was defined as (1) the slope of the radioactivity disappearance curve $\left(k_{1}\right)$ in the first reference period before vibration, (2) the slope $\left(\mathrm{k}_{2}\right)$ in the test period, and (3) the steepest slope $\left(\mathrm{k}_{3}\right)$ in the second reference period after exposure to vibration. The rate constants were computed from the regression line calculated from the "least square" method. The slowing down of the washout during vasoconstriction was described numerically by the change factor $F$ defined $a^{12}$ :

$$
F=\frac{k_{2}}{0.5 \times\left(k_{1}+k_{3}\right)} .
$$

Examples of washout curves are shown in the figure.

The difference in numerical values between men with VWF and male controls or between women with PRP and female controls was tested with the MannWhitney rank sum test. The difference in numerical values within a group was tested with the Wilcoxon

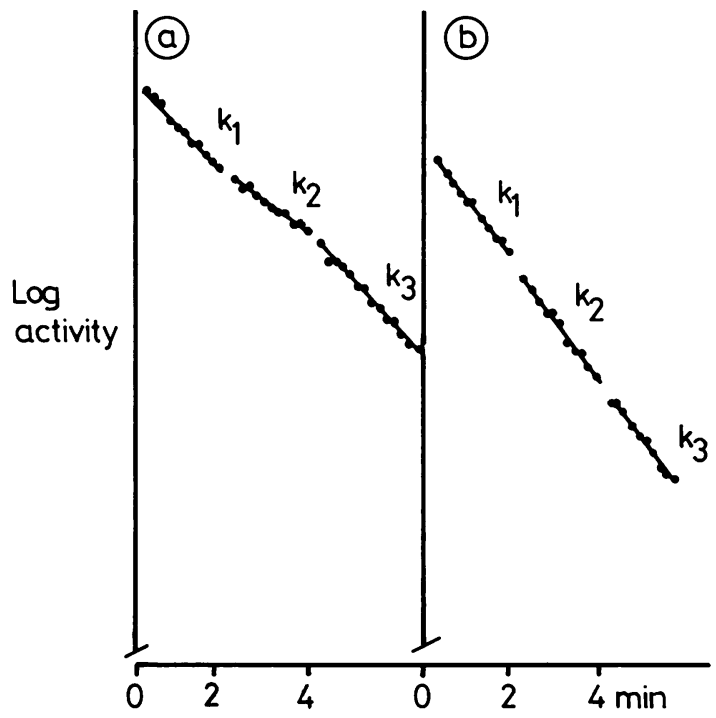

Examples of ${ }^{133}$ xenon washout curves with rate constant before $\left(k_{1}\right)$, during $\left(k_{2}\right)$, and after $\left(k_{3}\right)$ acute vibration exposure of finger. Change factor, $F$, was calculated as:

$$
\mathrm{F}=\frac{\mathrm{k}_{2}}{0.5 \times\left(\mathrm{k}_{1}+\mathrm{k}_{3}\right)} .
$$

(a): Exposure in a woman with primary Raynaud's phenomenon $(F=0.63)$. (b): Exposure during proximal nerve block in a woman with primary Raynaud's phenomenon $(F=1.03)$.
Table 2 Results of the vasoconstrictor response to acute vibration exposure without and during proximal nerve block. The results are expressed as the relative change in ${ }^{133}$ xenon washout rate constant $(F)$. Seven men with vibration induced white finger $(V W F)$, eight male controls $(M C)$, seven women with primary Raynaud's phenomenon (PRP), and 10 female controls (FC) were investigated. (Values are given as the median with the range in parentheses)

\begin{tabular}{llll}
\hline Group & $F$ & & $F$ \\
& Without nerve block & & During nerve block \\
\hline VWF & $0.84(0.80-0.97) \dagger$ & o & $1.01(0.97-1.09)$ \\
MC & $0.87(0.78-0.96) \dagger$ & o & $0.99(0.94-1.06)$ \\
PRP & $0.63(0.60-0.68)^{*}$ & o & $1.00(0.97-1.09)$ \\
FC & $0.87(0.79-0.99) \dagger$ & o & $1.09(0.93-1.14) \dagger$
\end{tabular}

* Significantly different from sex matched controls in same test $(\mathrm{p}<$ $0.01)$.

No other significant differences between sex matched groups in same test $(p>0 \cdot 10)$.

o Significant difference within a group $(p \leq 0.02)$.

$\dagger$ Significantly different from unity $(p<0.05)$.

matched pairs signed rank test. The correlation between the change factor, $F$, and age was tested with the Spearman rank correlation coefficient, $r_{s}$, in each of the four groups. A significance limit of 0.05 (twotailed) was used in all statistical tests. Values are given as median (range).

\section{Results}

In the control steady state experiments $F$ was 1.00 $(0.93-1 \cdot 10)$ and thus not different from unity $(\mathrm{p}>$ $0 \cdot 10$ ). Thus the requirement for a monoexponential washout rate during constant blood flow ${ }^{12}$ was considered to be fulfilled. The ratio between $\mathrm{k}_{3}$ and $\mathrm{k}_{1}$ did not differ significantly from unity in any of the four groups at both tests $(p>0 \cdot 10)$. Table 2 gives the results of the tests. When comparing the sex matched groups it is seen that blood flow decreases in response to exposure to vibration more in the PRP group than in the female controls, whereas blood flow decreases equally in the male groups. Nerve block inhibits the vasoconstrictor response to vibration in all four groups.

F was not correlated significantly with age in any of the four groups $(p>0 \cdot 10)$. Considering the age and sex matched subsamples the response to vibration without nerve block did not differ significantly between the two male groups $(p>0 \cdot 10)$, whereas the $F$ value of women with PRP was significantly smaller than that of female controls $(\mathrm{p}<0.05)$. During proximal nerve block the response did not differ between sex matched subgroups $(p>0 \cdot 10)$. Thus there is no reason for assuming that the results of table 2 could be explained by dependency on age. 


\section{Discussion}

In the present study exposure to acute vibration induced a vasoconstrictor response in the fingers of all four groups which was abolished during proximal nerve block. The results show the existence of a vibration elicited central sympathetic vasoconstrictor reflex in the normal finger and in fingers affected by PRP and VWF. The finding of an unchanged washout rate before and after vibration supports the assumption that the vasoconstriction is a consistent response to vibration and not a transient alteration in finger blood flow due to other stimuli. ${ }^{9}$ The vasoconstrictor response was normal in men with VWF and augmented in women with PRP when compared with that of their respective sex matched controls.

The finding of a vasoconstriction in controls is in accordance with other studies.' Welsh found in normal subjects that the finger adjacent to the vibration exposed finger had an undisturbed blood flow.' This might indicate a local vasoconstrictor mechanism. Hyvärinen et al found that vibration of one hand could induce a vasoconstriction in the contralateral fingers in subjects with VWF. ${ }^{2}$ This indicates a central reflex mechanism. The present results show that the vasoconstriction to acute vibration is due to a central sympathetic reflex in normal fingers and in fingers affected by VWF or PRP.

The augmented vasoconstrictor response to vibration found in subjects with PRP may be explained by a hyperreactivity of the nervous part of the reflex arch or of the arteriolar part. In a recent study we examined the postural vasoconstrictor reflexes in the same subjects and by the same washout technique as here. ${ }^{3}$ The results indicated a hyperreactivity of the central sympathetic nervous system and a normal function of digital arterioles and postganglionic sympathetic nerve fibres in both types of RP. Thus we need not assume an enhanced peripheral component of the reflex arch. The augmented vasoconstriction to vibration in PRP may freely be explained by the hyperreactivity of the central sympathetic nervous system. ${ }^{3}$ From our previous findings in subjects with VWF, an augmented vasoconstriction was to be expected as found in subjects with PRP because both groups showed signs of a hyperactivity of the central sympathetic nervous system. Nevertheless, a normal response to vibration was found in subjects with VWF. Why? Prolonged use of vibrating hand tools may have resulted in an adaptation of the central nervous system to vibration. This adaptation, however, seems to be poor ${ }^{13} \mathrm{~A}$ more likely explanation is that a vibration induced peripheral sensory neuropathy ${ }^{14}$ had depressed the vasoconstrictor response to a normal value. In a previous study the vasoconstriction to acute vibration exposure was measured by finger-pulse plethysmography in subjects with VWF. ${ }^{2}$ A decrease of the finger-pulse volume by $80 \%$ or more was considered abnormal. ${ }^{2}$ The investigation showed an abnormal reaction in $42 \%$ of the subjects with VWF. This is not contrary to the present result of subjects with VWF ( $p>0.05$, the Fisher test). It must further be taken into consideration that we measured the relative changes in cutaneous capillary blood flow during a two minute period whereas Hyvarinen et al measured indirectly reflections of changes in the total finger blood flow probably during shorter periods. ${ }^{2}$

Recently Taylor summarised the medicolegal difficulties of diagnosing VWF and noticed the poor understanding of the pathophysiological mechanisms. ${ }^{15}$ Neither the rewarming time ${ }^{16}$ nor the finger systolic blood pressure ${ }^{1718}$ in cold provocation tests has been found to distinguish between PRP and VWF. The present findings indicate that our vibration test may be of guidance. Investigations of the sympathetic vasoconstrictor reflexes elicited by exposure to acute vibration, by change in body posture ${ }^{3}$ and by venous stasis $^{3}$ may provide information of afferent, central, or postganglionic dysfunctions of the reflex arches in other types of RP and in other diseases.

The instrumentation for vibration exposure was placed at our disposal by the Brüel \& Kjær Company. The investigation was supported by the Fund of the Health Insurance Society and by the University of Copenhagen.

Requests for reprints to: Dr Niels Olsen, Department of Clinical Physiology and Nuclear Medicine, Rigshospitalet, Blegdamsvej 9, DK-2100 Copenhagen Ø.

\section{References}

1 Welsh CL. The effect of vibration on digital blood flow. Br J Surg 1980;67:708-10.

2 Hyvärinen J, Pyykkö I, Sundberg S. Vibration frequencies and amplitudes in the aetiology of traumatic vasospastic diseases. Lancet 1973; i:791-4.

3 Olsen N, Petring OU. Rossing N. Exaggerated postural vasoconstrictor reflex in Raynaud's phenomenon. Br Med $J$ 1987;294:1186-8.

4 Sejrsen P. Blood flow in cutaneous tissue in man studied by washout of radioactive xenon. Circulat Res 1969;25:215-29.

5 Allen EV, Brown GE. Raynaud's disease: a critical review of minimal requisites for diagnosis. Am J Med Sci 1932;183:187200.

6 Taylor W, Pelmear PL. Vibration white finger in industry. London: Academic Press, 1975: xvii-xxii.

7 Hirai M, Nielsen SL, Lassen NA. Blood pressure measurement of all five fingers by strain gauge plethysmography. Scand J Clin Lab Invest 1976;36:627-32.

8 Hirai MH. Arterial insufficiency of the hand evaluated by digital blood pressure and arteriographic findings. Circulation 1978;58:902-8.

9 Roddie IC. Circulation to skin and adipose tissue. In: Shepherd JT, Abboud FM, eds. Handbook of physiology. Section 2. The 
cardiovascular system. Vol III. Bethesda: American Physiological Society, 1983:285-317.

10 Grant RT, Bland EF. Observations on arteriovenous anastomoses in human skin and in the bird's foot with special reference to the reaction to cold. Heart 1929-31;15:385-411.

11 Sejrsen P. Atraumatic local labelling of skin by inert gas: epicutaneous application of xenon 133. J Appl Physiol 1968;24:570-2.

12 Henriksen O, Sejrsen P. Local reflex in microcirculation in human cutaneous tissue. Acta Physiol Scand 1976;98:227-31.

13 Hyvärinen J, Sakata H, Talbot WH, Mountcastle VB. Neuronal coding by cortical cells of the frequency of oscillating peripheral stimuli. Science 1968;162:1130-2.
14 Alaranta H, Seppäläinen AM. Neuropathy and the automatic analysis of electromyographic signals from vibration exposed workers. Scand J Work Environ Health 1977;3:128-34.

15 Taylor W. Vibration white finger: a newly prescribed disease. $\mathbf{B r}$ Med J 1985;291:921.

16 Welsh CL. Digital rewarming in the assessment of vibrationinduced white finger. Scand $J$ Work Environ Health 1986;12:249-50.

17 Nielsen SL. Significance of sympathetic nervous discharge in Raynaud's phenomenon. Clin Physiol 1981;suppl 1:79-83.

18 Olsen N, Fjeldborg P, Brøchner-Mortensen J. Sympathetic and local vasoconstrictor response to cold in vibration induced white finger. $\mathrm{Br} J$ Ind Med 1985;42:272-5. 